\title{
Morpho-Physical and Psycho-Social Determinants of Low Back Pain in Midwives Population in Benin
}

\author{
H. Etienne Alagnidé*, Natta D. Didier Niama, Herman Azanmasso, M. Germain Houngbedji, \\ E. Eric Dossa, G. Toussaint Kpadonou \\ Physical Medicine and RehabilitationDepartment of CNHU-HKM (Centre National Hospitalier et Universitaire-Hubert K. \\ MAGA), Cotonou, Benin \\ Email: *ealagnide@yahoo.fr
}

How to cite this paper: Alagnidé, H.E., Niama, D.D., Azanmasso, H., Houngbédji, M.G., Dossa, E.E. and Kpadonou, G.T. (2017) Morpho-Physical and Psycho-Social Determinants of Low Back Pain in Midwives Population in Benin. Open Journal of Therapy and Rehabilitation, 5, 107-117. https://doi.org/10.4236/ojtr.2017.54010

Received: August 30, 2017

Accepted: November 10, 2017

Published: November 13, 2017

Copyright $\odot 2017$ by authors and Scientific Research Publishing Inc. This work is licensed under the Creative Commons Attribution International License (CC BY 4.0).

http://creativecommons.org/licenses/by/4.0/

c) (i) Open Access

\begin{abstract}
Background: Low back pain is a real public health problem. Lots of studies have been done about it, but not in midwives group. The latter seem to be exposed to low back pain due to morphological, physical and psycho-social factors. We therefore study the place of these factors in the occurrence of low back pain in midwives. Method: Prospective, cross-sectional and analytical study, it is done with 102 midwives of university hospitals in Benin. They were interviewed and examined. An eventual link with their history of low back pain, for at least 3 months during the last 12 months before the study, was checked to their morphological aspects (spinal curvatures, BMI), physical examinations data (strength and muscular flexibility) and psycho-social factors (relationship with colleagues and either, stress, ...). The effect of these factors was assessed using relative risk (RR) with a $95 \%$ confidence interval. Results: Different morpho-physical and psychosocial disturbances were observed in midwives. $81 \%$ had a history of low back pain. The latter have a statistically significant relationship with the different factors studied. These were mostly exposure factors, but poor midwife relationship with their hierarchical superiors was a protective factor $(R R=0.69$ and $p=0.0106)$. Discussion-Conclusion: In Benin, health workers and especially midwives are very exposed to low back pain. The latter are often associated with different morphological, physical and psycho-social disturbances. The knowledge of those parameters is interesting to reduce this high prevalence of low back pain in midwives.
\end{abstract}

\section{Keywords}

Low Back Pain, Midwives, Nursing Staff, Psychosocial Disorders, 
Morpho-Physical Disturbances, Benin, Cotonou

\section{Introduction}

Low back pain is a real public health problem, more expensive than AIDS, cancer and cardiovascular diseases [1]. In general, it represents the most common reason for inability to work, especially among young people. Its causes are very varied. Activities of daily living and professional practices are often blamed. Its rate among health-care workers is very high and variable, around $60 \%-80 \%$ [2] [3] [4] [5] [6].

Midwives are a special group of healthcare workers. Indeed, they are subjected to high pressure, constant stress, adoption of postures and extreme positions. Unfortunately, from the literature review, we have not found any work on low back pain in this group, even if it has been reported that nurses in Gynecology and Obstetrics are more exposed than others [6] [7]. In Benin, a developing country, midwives are women who work in precarious conditions (lack of adapted ergonomic equipment, understaffing...). So, we aimed to study the prevalence of low-back pain in midwives in Benin, as well as morpho-physical and psycho-social factors linked to that illness.

\section{Patients and Method of Study}

Type of study and patients: It is a prospective, cross-sectional and analytical study. It's done during five (05) months, from the 1st of April to 31st of August 2010.

The study concerned midwives of university hospitals in Benin. It is about gynecological and obstetrical clinic of Hubert K. Maga's hospital (CNHU-HKM) and departmental hospitals of four out of six departments in Benin. It was departments of south and central (Atlantique, Mono, Oueme and Zou).

The minimal size $\mathrm{N}$ required for the study was calculated using Schwartz formula: $\mathrm{N}=\mathrm{z}^{2} \mathrm{pq} / \mathrm{d}^{2}$. [ $\mathrm{z}=$ standard normal deviate set at 1.96 that correspond to $95 \%$ confidence level; $\mathrm{p}=$ prevalence of low back pain in hospital staff. For that, we have chosen the prevalence of low back pain among hospital staff in Ouagadougou which is $56.4 \%$ (Ouédraogo DD et al., 2010); $\mathrm{q}=1-\mathrm{p}$ and $\mathrm{d}=$ error tolerated, set at $10 \%]$. So, $\mathrm{N}=1.96^{2} \times(0.564 \times 0.436) / 0.10^{2}=\mathbf{9 4 . 5}$.

Among one hundred and twenty-four (124) midwives staff during the study's period, one hundred and two (102) who have consented to participate and doesn't presented any of the exclusion criteria, were then enrolled. The exclusion criteria were: history of spinal traumatism (by road accident, sporting, surgery or other), pelvic limbs joints stiffness (osteoarthritis, rheumatoid arthritis, fractures, ...)

Study's different data were collected, using a systematic questionnaire, by face-to-face interview and clinical examination. 
Setting: Dependent variable of the study were the existence or not of low back pain history. The latter were considered to be present if within last twelve (12) months before the survey, midwives claimed to experience back pain for at least three (1) months.

Independent variables concerned morphological, physical and psycho-social factors of midwives.

The morphological factors studied were the column curvatures (cervical and lumbar) and Quetelet's body mass index (BMI). Column curvatures were measured (in centimeters) with a plumb's thread and a graduate plate ruler, on subject being standing, straight, shirtless (but with her bra). Their interpretation was made, according to the classification of Dufour and Gedda [8]. Indeed, the lumbar (and cervical) curvatures were said diminished, normal or increased, respectively according to whether their measure was less than $4 \mathrm{~cm}$ (or $3 \mathrm{~cm}$ ), 4 to $6.5 \mathrm{~cm}$ (or 3 to $4.5 \mathrm{~cm}$ ), or greater than $6.5 \mathrm{~cm}$ (or $4.5 \mathrm{~cm}$ ). To analyze influence of these variables on the existence or not of a low back pain history, cervical and lumbar curvatures were called pathological when they are diminished or increased.

Physical factors concerned strength and flexibility of certain muscles and regular practice of sport (at least once session of one hour per week). Muscle strength was studied according to the classical muscular testing with rating of 0 to 5, for Psoas and Iliacus muscles and gluteus maximus. It was said to be normal when testing was 4 or $5 / 5$ or diminished for less than $4 / 5$ testing (noted that nevertheless, strength of muscles explored in the midwives was less than 2/5). Muscle strength was evaluated on both sides. In the case of asymmetry, we consider the pathological result. For low back and abdominal wall muscles endurance, Biering-Sorensen and Ito-Shiraldo methods were used respectively [9] [10].

Muscle flexibility was explored by passively putting the member segment in a position contrary to that induced by the action of the muscle studied. For iliopsoas muscle, we carried out the test of Thomas: Patient was lied on her back, (tested side's knee extended), we realize a complete flexion of the contralateral hip (knee of this side being also maintained in complete flexion). The separation of the popliteal depression on the side to be tested from the examination table was measured using a graduate ruler. Iliopsoas flexibility was said to be normal for a detachment of less than $5 \mathrm{~cm}$. To test tensor of facialatae flexibility, we carried out Ober test. Patient was lied on the opposite side, the examiner behind the patient, stabilizes the pelvis with her cranial hand and with her caudal hand, he cradles knee of tested side which is bent at $90^{\circ}$. From this position, examiner performed hip abduction and then extension before living the limb go. Normally, a fall of the thigh is expected; if not, we say that flexibility of tensor fasciae latae muscle is diminished. For hamstrings flexibility, it was appreciated by the popliteal angle on a patient lied on his back. It's said diminished, for popliteal angle less than $160^{\circ}$. As for the iliopsoas and gluteus maximus strength, flexibility of 
these different muscles were assessed on both sides. In the case of asymmetry, we consider the pathological result.

Psycho-social parameters were collected by face-to-face interview. They took into account the impression for the patient to be stressed at work, overworked, to have family difficulties (with her spouse and/or children) or to have good socio-professional relationships with his superiors, colleagues and immediate neighbors.

Data analysis: Data collected were encoded and analyzed in Epi-info version 3.5.1. Data's analysis was first univariate: numbers and proportions of the qualitative variables, averages and extremes of quantitative variables. Then, we performed a bivariate analysis to assess the influence of different variables on the existence or not of a low back pain history. For this purpose, each of the independent variables has been dichotomized. Chi-square test $\left(\mathrm{X}^{2}\right)$ or Ficher test (when $\mathrm{X}^{2}$ conditions were not met) was used. The effect of variables that had a statistically significant difference on history of low back pain was investigated by the relative risk (RR) factor. The confidence interval for this $95 \%$ relative risk $\left(\mathrm{RR}-\mathrm{CI}_{95 \%}\right)$ was also determined. The threshold of significance chosen was $5 \%$.

\section{Results}

\subsection{Midwives Characteristics}

Midwives were aged 24 to 66 years with an average of $41.41 \pm 2.7$ years. Their BMI was 14.2 to $43.3 \mathrm{~kg} / \mathrm{m}^{2}$ with an average of $29.5 \mathrm{~kg} / \mathrm{m}^{2}$. Table 1 presents morpho-physical and psycho-social characteristics of these women. It appears that many of midwives of the series have abnormalities of spinal curvatures (about $60 \%$ ), a decrease of muscle flexibility predominantly on Iliopsoas (70\%), in the strength of the trunk and pelvic muscles (40\% - 50\%), and. Only one out of ten midwives regularly practice sport. If the majority say that they have good socio-professional relationships, they admit their stress and overflow to work (70\%).

\subsection{Low Back Pain History}

Eighty-three (83) participants (81.40\%), midwives suffered of low back pain at least three months within last twelve's one. Figure 1 shows the distribution of these midwives low back pain intensity.

\subsection{Factors Linked to Low Back Pain in Midwives}

They are presented on Table 2 and Table 3. Among psychosocial factors studied, relationships with colleagues, family difficulties and stress do not seem to influence history of low back pain. But it is linked to abnormalities of column curvature (especially lumbar), muscle weakness (low back and iliopsoas) and especially muscle diminished flexibility and lack of regular sports practice As shown on Table 4, between different morpho-physical and psycho-social factors related to low back pain in midwives, precarious relationships with hierarchical 
Table 1. Distribution of midwives in the study according to their morpho-physical and psycho-social characteristics.

\begin{tabular}{|c|c|c|c|c|}
\hline & & & Numbers & Proportions (\%) \\
\hline & \multirow{2}{*}{ Quetelet's BMI } & Less than $30 \mathrm{~kg} / \mathrm{m}^{2}$ & 62 & 60.8 \\
\hline & & Greater than $30 \mathrm{~kg} / \mathrm{m}^{2}$ & 40 & 39.2 \\
\hline \multirow{9}{*}{ 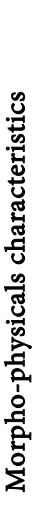 } & \multirow{3}{*}{ Column curvatures } & Normal in cervical & 45 & 44.1 \\
\hline & & Normal in lumbar & 38 & 37.3 \\
\hline & & Iliopsoas & 66 & 64.7 \\
\hline & \multirow{4}{*}{$\begin{array}{l}\text { Normal } \\
\text { muscular strength }\end{array}$} & Gluteus maximus & 60 & 58.8 \\
\hline & & Lower back muscles & 58 & 56.9 \\
\hline & & Abdominal wall muscles & 53 & 52.0 \\
\hline & & Hamstrings muscles & 55 & 54.0 \\
\hline & \multirow[t]{2}{*}{ Normal muscle flexibility } & Tensorfacialata & 51 & 50.0 \\
\hline & & Iliopsoas & 33 & 32.4 \\
\hline \multirow{7}{*}{ 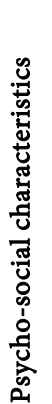 } & \multicolumn{2}{|c|}{ Sport regular practice } & 12 & 11.8 \\
\hline & \multirow{3}{*}{$\begin{array}{l}\text { Good socio-professional } \\
\text { relationship with: }\end{array}$} & Colleagues & 91 & 89.2 \\
\hline & & Neighbors/Co-habitants & 83 & 81.4 \\
\hline & & Hierachical superiors & 70 & 68.6 \\
\hline & \multicolumn{2}{|c|}{ Perceived-work stress } & 71 & 69.6 \\
\hline & \multicolumn{2}{|c|}{ Overflow to work } & 66 & 64.7 \\
\hline & \multicolumn{2}{|c|}{ Experience of family difficulties } & 41 & 40.2 \\
\hline
\end{tabular}

\section{Low back pain intensity}

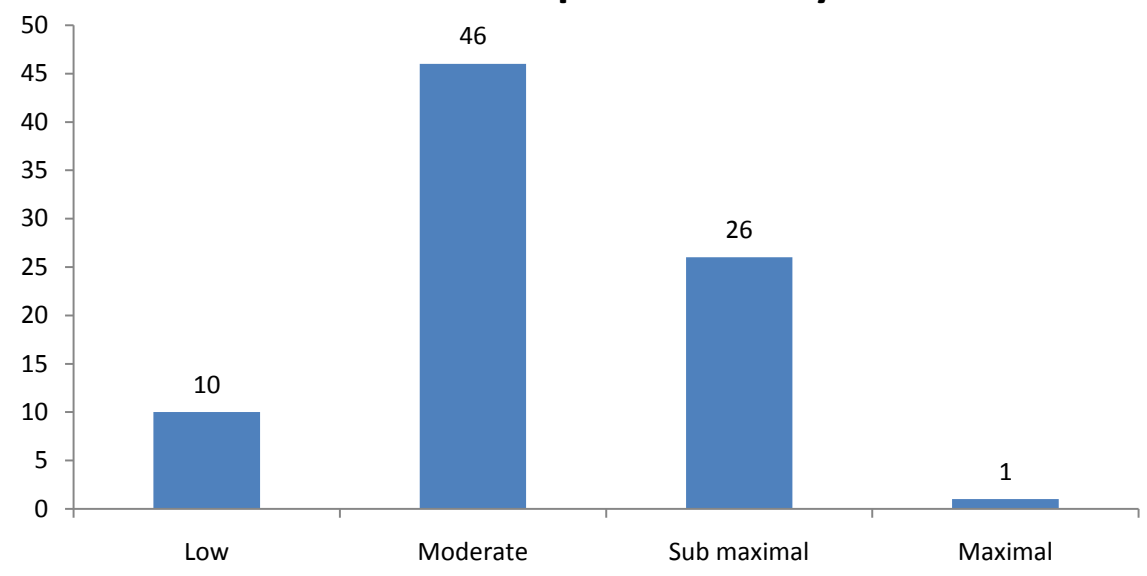

Figure 1. Low back pain intensity in midwives population.

superiors seem rather to have a protective effect $(R R=0.69$ and $p=0.0106)$.

\section{Discussion}

Column curvatures abnormalities are very frequent in our series. The large proportion of pelvic and trunk muscles weakness and diminished flexibility is 
Table 2. Study of the influence of morpho-physical characteristics of midwives on the existence or not of their history of low back pain.

\begin{tabular}{|c|c|c|c|c|}
\hline & & \multicolumn{2}{|c|}{ LBP history } & \multirow{2}{*}{ Statistical test } \\
\hline & & Yes & No & \\
\hline \multirow{2}{*}{ BMI $\left(\mathrm{kg} / \mathrm{m}^{2}\right)$} & Less than 30 & 49 & 13 & $\mathrm{X}^{2}=0.57$ \\
\hline & Greater than 30 & 34 & 6 & $\mathrm{p}=0.45$ \\
\hline \multirow{2}{*}{ Cervical curvature } & Normal & 33 & 12 & $\mathrm{X}^{2}=3.43$ \\
\hline & Pathological & 50 & 7 & $\mathrm{p}=0.06$ \\
\hline \multirow{2}{*}{ Lumbar curvature } & Normal & 24 & 14 & $\mathrm{X}^{2}=13.26$ \\
\hline & Pathological & 59 & 5 & $p=0.0003$ \\
\hline \multicolumn{5}{|l|}{ Muscle endurance } \\
\hline \multirow{2}{*}{ Low back muscles } & Normal & 42 & 16 & $\mathrm{X}^{2}=7.12$ \\
\hline & Diminished & 41 & 3 & $p=0.0076$ \\
\hline \multirow{2}{*}{ Abdominal wall muscles } & Normal & 40 & 13 & $\mathrm{X}^{2}=2.53$ \\
\hline & Diminished & 43 & 6 & $\mathrm{p}=0.11$ \\
\hline \multicolumn{5}{|l|}{ Muscle strength } \\
\hline \multirow{2}{*}{ Gluteus maximus } & Normal & 46 & 14 & $\mathrm{X}^{2}=2.13$ \\
\hline & Diminished & 37 & 5 & $\mathrm{p}=0.14$ \\
\hline \multirow{2}{*}{ Iliopsoas } & Normal & 48 & 18 & $\mathrm{X}^{2}=9.22$ \\
\hline & Diminished & 35 & 1 & $\mathrm{p}=0.0024$ \\
\hline \multicolumn{5}{|l|}{ Muscle flexibility } \\
\hline \multirow{2}{*}{ Iliopsoas } & Normal & 20 & 13 & $\mathrm{X}^{2}=13.88$ \\
\hline & Diminished & 63 & 6 & $\mathrm{p}=0.0002$ \\
\hline \multirow{2}{*}{ Hamstrings muscles } & Normal & 38 & 17 & $\mathrm{X}^{2}=11.88$ \\
\hline & Diminished & 45 & 2 & $\mathrm{p}=0.0006$ \\
\hline \multirow{2}{*}{ Tensorfacialata } & Normal & 37 & 14 & $\mathrm{X}^{2}=5.24$ \\
\hline & Diminished & 46 & 5 & $\mathrm{p}=0.0221$ \\
\hline \multirow{2}{*}{ Regular sport practice } & Yes & 0 & 12 & $P=0.0000$ \\
\hline & No & 83 & 7 & (Fischer) \\
\hline
\end{tabular}

consistent with that result. Studies, covering a population of low back pain subjects, show greater proportions of muscular diminished flexibility (63\% to $77 \%$ ) [11] [12].

In Lebanon, 33\% of health-workers, included by Ghoussoub et al., practice sports activities [13]. Our low proportion of sporting practice could be explained by the fact that in Africa the practice of sport is not yet a priority. And especially for African women, various socio-cultural considerations needed to be considered (domestic occupations, clothing...). As reported by Ouedraogo et al., sports practice is a protecting factor against low back pain [5].

Several psychological factors were evaluated. They pointed out that $69.6 \%$ of 
Table 3. Study of the influence of psycho-social characteristics of midwives on the existence or not of their history of low back pain.

\begin{tabular}{|c|c|c|c|c|}
\hline & & \multicolumn{2}{|c|}{ Low back pain history } & \multirow{2}{*}{ Statistical tests } \\
\hline & & Yes & No & \\
\hline \multirow{2}{*}{ Relationship with hierarchical superiors } & Good & 63 & 7 & $\mathrm{X}^{2}=10.96$ \\
\hline & Bas & 20 & 12 & $\mathrm{p}=0.0009$ \\
\hline \multirow{2}{*}{ Relationship with colleagues } & Good & 76 & 15 & \multirow{2}{*}{$\mathrm{P}=0.97$ (Fischer) } \\
\hline & Bas & 7 & 4 & \\
\hline \multirow{2}{*}{ Relationship with neighbors } & Good & 65 & 18 & \multirow{2}{*}{$\begin{array}{c}P=0.08 \\
\text { (Fischer) }\end{array}$} \\
\hline & Bas & 18 & 1 & \\
\hline \multirow{2}{*}{ Overflow to work } & Yes & 61 & 5 & \multirow{2}{*}{$\begin{array}{l}X^{2}=15.07 \\
p=0.0002\end{array}$} \\
\hline & No & 22 & 14 & \\
\hline \multirow{2}{*}{ Family difficulties } & Yes & 33 & 8 & \multirow{2}{*}{$\begin{array}{c}\mathrm{X}^{2}=0.04 \\
\mathrm{p}=0.85\end{array}$} \\
\hline & No & 50 & 11 & \\
\hline \multirow{2}{*}{ Stress to work } & Yes & 60 & 11 & $\mathrm{X}^{2}=1.51$ \\
\hline & No & 23 & 8 & $\mathrm{p}=0.22$ \\
\hline
\end{tabular}

Table 4. Summary of effect of significant exposure factors on low back pain in study subjects.

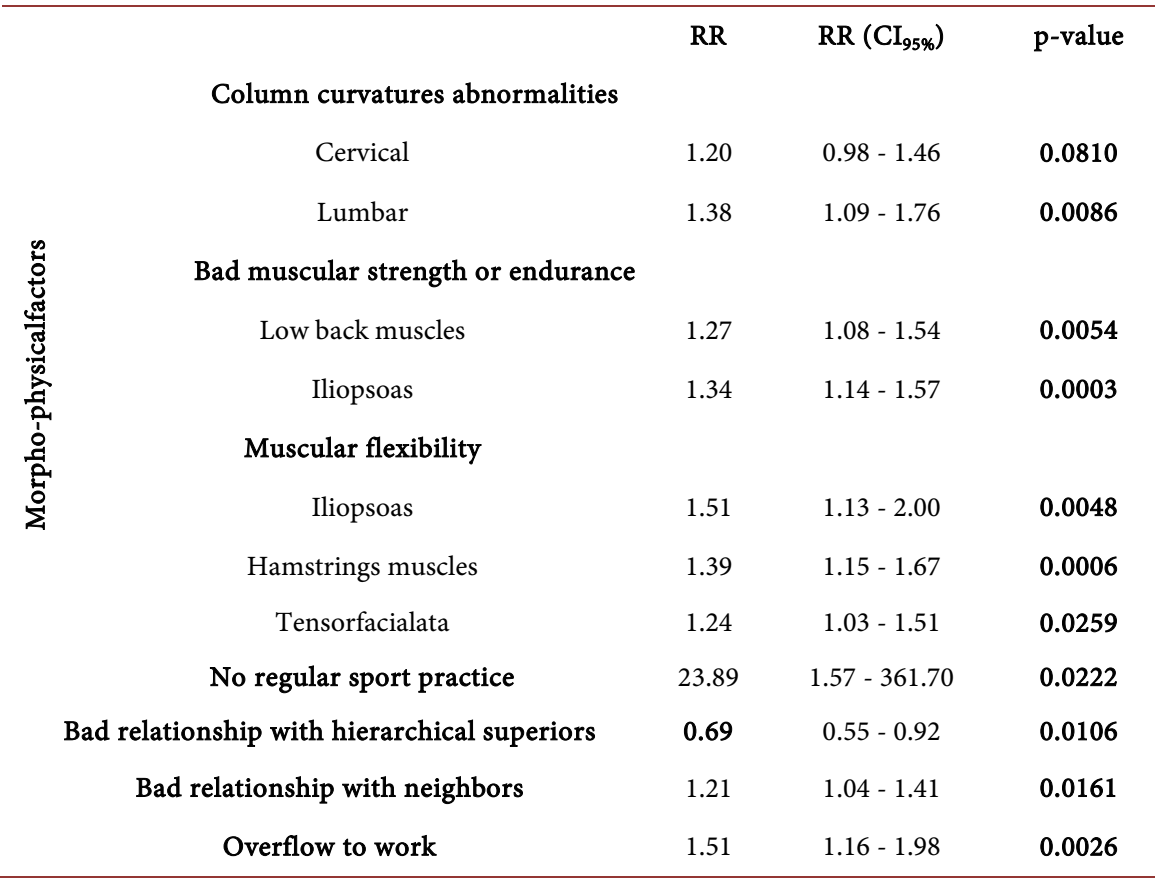

the participants were very stressed during their duties. This result may be explained by the fact that midwives are constrained at each delivery to a dual task: to be able to safeguard not only the life of the mother but also the newborn's one. Also, the overflow at work reported by wives could contribute to the stress. The latter exposed to low back pain [3]. 
Low back pain's rate in health-workers around literature reviews is very disparate: $33 \%$ to $86.4 \%$ [3] [4] [5] [6] [7] [13]-[18]. That large gap can be explained by differences in health-workers studied, type of low back pain (acute or chronic), period and mode of data collection ... In all cases, unanimity is made on the issue of special exposure of health workers. Would it be fair to say that these health actors have a great exposure because of their different postures during professional practices? But normally, aren't they supposed to know more about these harmful postures to the spine? This certainly confirms the old popular saying "shoemakers are the worst off". Sikiru and Shmaila noted that these agents have little knowledge of back hygiene measures [6]. We reported $81.4 \%$ of low back pain in our series. This predominance is slightly higher than those seen in lot of studies. The greater proportion of cases of low back pain observed in our series could be related to the different morphological, physical and psychosocial perturbations.

Christie et al. have reported, using a photographic technique, that low back pain is correlated with lumbar curvature [19]. The importance of lumbar spine stabilizers in low back pain has been amply demonstrated [20] [21] [22] [23]. Our study does not show a significant relationship between low back pain with gluteus maximus and low back muscles strength. These results could be justified by the importance of muscle synergy (agonist/antagonist) for lumbar spinal stabilization. That means, it is not the weakness of one or the retraction of the other, but merely the breaking of a balance. About importance of controlled and adapted physical and sports activities, several authors have also reported it [24] [25].

From our psycho-social factors, the lack of good relationships with colleagues, daily stress and family difficulties reported do not appear to be significantly correlated with a history of low back pain. Would these women find other strategies to deal with psychological difficulties in these situations? Indeed, according to several authors stress is generally linked with low back pain [3] [26] [27]. But as us, Shieh et al. [28] showed that overload at work is significantly linked with the occurrence of low back pain. Perceived-work stress and overflow to work are they in relationship with work enjoyment? In Hong Kong, neither enjoyed their work is a risk factor for low back pain [18].

Table 4 shows that all factors, whether morpho-physical or psycho-social, linked with low back pain have a deleterious effect with regard to the occurrence of these low back pain ( $R R>1$ and $p<0.05$ ). It was surprising for us to observe the rather protective effect of precarious relationships with the midwives' hierarchical superiors with a history of low back pain $(R R=0.69$ and $p=0.0106)$. That result noted that low back pain's physiopathology can't be explained only with one situation: it's a multifactorial pathology.

\section{Conclusion}

In Benin, as in many other countries, an important proportion of midwives ex- 
perience low back pain episodes. The latter were influenced by different morphological, physical, psychological and social factors. The direct involvement of their professional practice in the occurrence of these lower back pain attacks can't be demonstrated by this study. In any case, our results should concern this health professional class and various actors of their management, in order to find the appropriate means to reduce this high prevalence of low back pain in midwives population.

\section{Acknowledgements}

This study could not be possible without those persons that we sincerely acknowledge:

- Midwives who consent time and others to be include in the study.

- Director of Hubert K. Maga's hospital (CNHU-HKM) of Cotonou and those of Atlantique, Mono, Zou and Oueme departmental hospitals in Benin for their permission for the study.

\section{Conflicts of Interest}

Authors declared they have no conflict of interest.

\section{References}

[1] Epping-Jordan, J.E. (1998) Transition to Chronic Pain in Men with Low Back Pain: Predictive Relationship among Pain Intensity, Disability and Depressive Symptoms. Health Psychology, 17, 421-427. https://doi.org/10.1037/0278-6133.17.5.421

[2] Gatchel, R.J., Polatin, P.B. (1995) and Mayer, T.G. The Dominant Role of Psychosocial Risk Factors among in the Development of Chronic Low Back Pain Disability. Spine, 20, 2702-2709. https://doi.org/10.1097/00007632-199512150-00011

[3] Karahan, A., Kav, S., Abbasoglu, A. and Dogan, N. (2009) Low Back Pain: Prevalence and Associated Risk Factors among Hospital Staff. Journal of Advanced Nursing, 65, 516-524. https://doi.org/10.1111/j.1365-2648.2008.04905.x

[4] Mitchell, T., O’Sullivan, P.B., Burnett, A.F., et al. (2008) Low Back Pain Characteristics from Undergraduate Student to Working Nurse in Australia: A Cross-Sectional Survey. International Journal of Nursing Studies, 45, 1636-1644. https://doi.org/10.1016/j.ijnurstu.2008.03.001

[5] Ouedraogo, D.D., Ouedraogo, V., Ouedraogo, L.T., et al. (2010) Prevalence and Factors Associated with Low Back Pain among Hospital Staff in Ouagadougou (Burkina Faso). Medecine Tropicale, 70, 277-280.

[6] Sikiru, L. and Shmaila, H. (2009) Prevalence and Risk Factors of Low Back Pain among Nurses in Africa: Nigerian and Ethiopian Specialized Hospitals Survey Study. East African Journal of Public Health, 6, 22-25. https://doi.org/10.4314/eajph.v6i1.45737

[7] Marena, C., Gervino, D., Pistorio, A., et al. (1997) [Epidemiologic Study on the Prevalence of Low Back Pain in Health Personnel Exposed to Manual Handling Tasks.] Giornale Italiano di Medicina del Lavoro ed Ergonomia, 19, 89-95.

[8] Michel, D. (2007) Dictionnaire de la kinésithérapie et réadaptation Maloine. [Dictionary of Physiotherapy and Rehabilitation.] 582 p. 
[9] Biering-Sørensen, F. (1984) Physical Measurements as Risk Indicators for Low-Back Trouble over a One Year Period. Spine, 9, 106-119. https://doi.org/10.1097/00007632-198403000-00002

[10] Ito, T., Shirado, O., Suzuki, H., et al. (1996) Lumbar Trunk Muscle Endurance Testing: An Inexpensive Alternative to a Machine for Evaluation. Archives of Physical Medicine and Rehabilitation, 77, 75-79.

[11] Onuwe, H.A. (2000) (LBP) Low Back Pain during Activities of Daily Living (ADL) A Etiology, Prevention and Physical Treatment. Journal of the Nigeria Medical Rehabilitation Therapist, 5, 17-20.

[12] Ramond-Roquin, A., Pecquenard, F., Schers, H., et al. (2015) Psychosocial, Musculoskeletal and Somatoform Comorbidity in Patients with Chronic Low Back Pain: Original Results from the Dutch Transition Project. Family Practice, 32, 297-304. https://doi.org/10.1093/fampra/cmv027

[13] Ghoussoub, K., El Asmar, A., Kreichati, G., et al. (2016) Prevalence and Risk Factors Associated with Low Back Pain among Hospital Staff in a University Hospital in Lebanon. Annals of Physical and Rehabilitation Medicine, 59S, e146.

[14] Cinar-Medeni, O., Elbasan, B. and Duzgun, I. (2016) Low Back Pain Prevalence in Healthcare Professionals and Identification of Factors Affecting Low Back Pain. Journal of Back and Musculoskeletal Rehabilitation, 1-6.

[15] Mehrdad, R., Shams-Hosseini, N.S., Aghdaei, S. and Yousefian, M. (2016) Prevalence of Low Back Pain in Health Care Workers and Comparison with Other Occupational Categories in Iran: A Systematic Review. Iranian Journal of Medical Sciences, 41, 467-478.

[16] Cougot, B., Petit, A., Paget, C., et al. (2015) Chronic Low Back Pain among French Healthcare Workers and Prognostic Factors of Return to Work (RTW): A Non-Randomized Controlled Trial. Journal of Occupational Medicine and Toxicology, 10, 40. https://doi.org/10.1186/s12995-015-0082-5

[17] Omokhodion, F.O., Umar, U.S. and Ogunnowo, B.E. (2000) Prevalence of Low Back Pain among Staff in a Rural Hospital in Nigeria. Occupational Medicine, 50, 107-110. https://doi.org/10.1093/occmed/50.2.107

[18] Yip, Y. (2001) A Study of Work Stress, Patient Handling Activities and the Risk of Low Back Pain among Nurses in Hong Kong. Journal of Advanced Nursing, 36, 794-804. https://doi.org/10.1046/j.1365-2648.2001.02037.x

[19] Christie, H.J., Kumar, S. and Warren, S.A. (1995) Postural Aberation in Low Back Pain. Archives of Physical Medicine and Rehabilitation, 75, 218-224.

[20] Southwell, D.J., Hills, N.F., McLean, L. and Graham, R.B. (2016) The Acute Effects of Targeted Abdominal Muscle Activation Training on Spine Stability and Neuromuscular Control. Journal of NeuroEngineering and Rehabilitation, 13, 19. https://doi.org/10.1186/s12984-016-0126-9

[21] Teyhen, D.S., Bluemle, L.N., Dolbeer, J.A., et al. (2009) Changes in Lateral Abdominal Muscle Thickness during the Abdominal Drawing-in Maneuver in Those with Lumbopelvic Pain. The Journal of Orthopaedic and Sports Physical Therapy, 39, 791-798. https://doi.org/10.2519/jospt.2009.3128

[22] Martuscello, J.M., Nuzzo, J.L., Ashley, C.D., et al. (2013) Systematic Review of Core Muscle Activity during Physical Fitness Exercises. The Journal of Strength \& Conditioning Research, 27, 1684-1698. https://doi.org/10.1519/JSC.0b013e318291b8da

[23] Beimborn, D.S. and Morrissey, M.C. (1988) A Review of the Literature Related to 
Trunk Muscle Performance. Spine, 13, 655-660.

https://doi.org/10.1097/00007632-198813060-00010

[24] Van Tulder (1997) Conservative Treatment of Acute and Chronic Nonspecific Low Back Pain. A Systematic Review of Randomized Controlled Trials of the Most Common Interventions. Spine, 22, 2128-2156. https://doi.org/10.1097/00007632-199709150-00012

[25] De souza, F. and Roland, B. (2000) Associations of Physical Activity and Inactivity with Low Back Pain in Adolescents. Scandinavian Journal of Medicine \& Science in Sports, 18, 188-194.

[26] Stubbs, B., Koyanagi, A., Thompson, T., et al. (2016) The Epidemiology of Back Pain and Its Relationship with Depression, Psychosis, Anxiety, Sleep Disturbances, and Stress Sensitivity: Data from 43 Low- and Middle-Income Countries. General Hospital Psychiatry, 43, 63-70.

[27] Heidari, J., Mierswa, T., Kleinert, J., et al. (2016) Parameters of Low Back Pain Chronicity among Athletes: Associations with Physical and Mental Stress. Physical Therapy in Sport, 21, 31-37.

[28] Shieh, S.H., Sung, F.C., Su, C.H., et al. (2016) Increased Low Back Pain Risk in Nurses with High Workload for Patient Care: A Questionnaire Survey. Taiwanese Journal of Obstetrics and Gynecology, 55, 525-529. 